\title{
Mechanisms of Disease: Host-Pathogen Interactions between Burkholderia Species and Lung Epithelial Cells
}

\author{
Jonathan David $^{1 *}$, Rachel E. Bell ${ }^{1,2}$ and Graeme C. Clark ${ }^{1}$ \\ ${ }^{1}$ Microbiology, Biomedical Sciences, Defence Science and Technology Laboratory, Salisbury, UK, ${ }^{2}$ Division of Immunology, \\ Infection and Inflammatory Disease, Centre for Molecular and Cellular Biology of Inflammation, King's College London, \\ London, UK
}

Members of the Burkholderia species can cause a range of severe, often fatal, respiratory diseases. A variety of in vitro models of infection have been developed in an attempt to elucidate the mechanism by which Burkholderia spp. gain entry to and interact with the body. The majority of studies have tended to focus on the interaction of bacteria with phagocytic cells with a paucity of information available with regard to the lung epithelium. However, the lung epithelium is becoming more widely recognized as an important player in innate immunity and the early response to infections. Here we review the complex relationship between Burkholderia species and epithelial cells with an emphasis on the most pathogenic species, Burkholderia pseudomallei and Burkholderia mallei. The

OPEN ACCESS

Edited by:

Chad J. Roy,

Tulane University School of Medicine,

USA

Reviewed by:

Tonyia Eaves-Pyles,

University of Texas Medical Branch,

USA

Glen C. Ulett,

Griffith University, Australia

*Correspondence:

Jonathan David

jdavid@dstl.gov.uk

Received: 11 August 2015 Accepted: 30 October 2015 Published: 18 November 2015

Citation:

David J, Bell RE and Clark GC (2015) Mechanisms of Disease:

Host-Pathogen Interactions between

Burkholderia Species and Lung Epithelial Cells.

Front. Cell. Infect. Microbiol. 5:80. doi: 10.3389/fcimb.2015.00080 current gaps in knowledge in our understanding are highlighted along with the epithelial host-pathogen interactions that offer potential opportunities for therapeutic intervention.

Keywords: Burkholderia, epithelium, epithelial, lung, host-pathogen interaction

\section{INTRODUCTION}

The lung epithelium is increasingly being acknowledged as having an important and complex role in protecting the body from infection. Aside from the obvious physical barrier properties the epithelium offers to the underlying endothelium and circulatory system, this region of the lung is also thought to have immunomodulatory roles which help during both the early phases of infection and aid in the resolution of the host response (Tam et al., 2011). Having a clear understanding of how microorganisms interact with the different regions within the lung will be essential in order to design new or novel medical treatments for combating infection. In order to achieve this aim a plethora of in vitro cell models have been developed in order to study infectious diseases.

\section{MODELING THE RESPIRATORY TRACT}

Epithelial cells change in their morphology and function throughout the respiratory tract. As a consequence, a range of different in vitro systems have been developed for oral, nasal, laryngeal, mucoepidermoid, bronchiolar, and alveolar cells in order to establish the architecture and key roles of each region within the tract. However, these models also provide a vital means of establishing how infectious organisms can interact with this first line of defense in the body. As bacteria travel 
the length of the respiratory tract they will come into contact with these epithelial cells but also other cell types including; lymphocytes and macrophages in the sub-epithelia region, mucosa-associated lymphoid tissue (MALT), bronchi-associated lymphoid tissue (BALT), basal cells, goblet cells, Clara cells, and alveolar macrophages. As the infection continues to progress, further immune cells (e.g., lymphocytes, eosinophils, and neutrophils) migrate into the lung. The lung environment is a complex construct of structural, secretory, and immune cells with all of these cells having the potential to interact with bacteria. This review focuses solely on the interactions of the lung epithelium with the Genera Burkholderia.

Epithelial cells are ubiquitous in the body and line many mucosal and tissue surfaces, including the respiratory tract. The epithelial layer is a vital barrier for protection against infection and cells are closely associated by tight junctions and other adherins (Parker and Prince, 2011). In the case of the respiratory tract, the epithelial layer is the primary defense against inhaled pathogens and is important to study the process of lung infections (Burns et al., 1996). Various in vitro models of infection have been developed to date to study the interactions between the host cells and Burkholderia spp. (Table 1; Eagle et al., 1956; Moorhead, 1965; Stoner et al., 1975; Lieber et al., 1976; Fogh et al., 1977; Carney et al., 1985; Chen, 1988; Reddel et al., 1988; Zeitlin et al., 1991; Cozens et al., 1994). Burkholderia pseudomallei in particular has a broad tropism for epithelial cells. The organism can adhere to a range of human epithelial cell lines in vitro including those derived from alveolar, bronchial, laryngeal, oral, conjunctiva, and cervical locations (Brown et al., 2002; Essex-Lopresti et al., 2005). As well as acting as an important physical barrier from infection, epithelial cells can also produce a range of products that can either directly or indirectly affect bacterial colonization and survival within in the lung, through the activation of arms of the innate response. These include antimicrobial products that act directly upon the invading organism and/or through the release of various cytokines in order to instigate an immune response leading to the recruitment of circulating monocytes required for the clearance of infection (Parker and Prince, 2011; Vareille et al., 2011). These direct and indirect responses will now be considered in more detail in the context of infections with Burkholderia spp. Whilst general interactions such as adherence, invasion and intracellular replication of the Burkholderia spp. have been consistently seen in a variety of cell types; it is also important to acknowledge cell specificity. Table 2 summarizes the research to date in this context.

\section{THE PATHOGENIC BURKHOLDERIA SPECIES}

Burkholderia is a genus of Gram-negative Proteobacteria containing approximately 30 species. These species are associated with a range of diseases of varying severity in animals, plants and humans; often utilizing the lungs as the primary route of entry into the body. Of particular interest are B. pseudomallei and $B$. mallei, due to the severity of the diseases that they
TABLE 1 | Lung epithelial cell models used for studying Burkholderia infection.

\begin{tabular}{|c|c|c|c|}
\hline Cell type & Species & Lung location & Derivation \\
\hline A549 & Human & Alveolar & $\begin{array}{l}\text { A type 2-like pneumocyte derived } \\
\text { from adenocarcinoma (Lieber } \\
\text { et al., 1976) }\end{array}$ \\
\hline LA-4 & Mouse & Alveolar & $\begin{array}{l}\text { A type 2-like pneumocyte derived } \\
\text { from adenocarcinoma (Stoner } \\
\text { et al., 1975) }\end{array}$ \\
\hline $16 \mathrm{HBE}$ & Human & Bronchiolar & $\begin{array}{l}\text { SV40 transformed bronchial } \\
\text { epithelium (Cozens et al., 1994) }\end{array}$ \\
\hline Calu-3 & Human & Bronchiolar & $\begin{array}{l}\text { Derived from a bronchial epithelial } \\
\text { adenocarcinoma (Fogh et al., } \\
\text { 1977) }\end{array}$ \\
\hline BEAS-2B & Human & Bronchiolar & $\begin{array}{l}\text { SV40/adenovirus } 12 \text { transformed } \\
\text { bronchial epithelium (Reddel } \\
\text { et al., 1988) }\end{array}$ \\
\hline CFBE & Human & Bronchiolar & $\begin{array}{l}\text { SV40/adenovirus } 12 \text { transformed } \\
\text { cystic fibrosis bronchial epithelial } \\
\text { cell line (Zeitlin et al., 1991) }\end{array}$ \\
\hline $\mathrm{NCl}-\mathrm{H} 292$ & Human & Mucoepidermoid & $\begin{array}{l}\text { Derived from a cervical node } \\
\text { metastasis of a pulmonary } \\
\text { mucoepidermoid carcinoma. } \\
\text { These cells contain numerous } \\
\text { small mucin-containing granules } \\
\text { (Carney et al., 1985) }\end{array}$ \\
\hline HEp-2 & Human & Laryngeal & $\begin{array}{l}\text { Originally thought to be from a } \\
\text { laryngeal carcinoma it is now } \\
\text { known to be established via HeLa } \\
\text { cell contamination* (Chen, 1988) }\end{array}$ \\
\hline RPMI-2650 & Human & Nasal & $\begin{array}{l}\text { Derived from a malignant tumor } \\
\text { of the nasal septum (Moorhead, } \\
\text { 1965) }\end{array}$ \\
\hline KB & Human & Oral & $\begin{array}{l}\text { Originally thought to be from a } \\
\text { carcinoma of the mouth it is now } \\
\text { known to be established via HeLa } \\
\text { cell contamination* (Eagle et al., } \\
\text { 1956) }\end{array}$ \\
\hline Primary & Any & Any & $\begin{array}{l}\text { Derived and cultured directly from } \\
\text { tissue. Primary cells initially retain } \\
\text { phenotypic characteristics of the } \\
\text { donor tissue but do differentiate } \\
\text { post isolation leading to variation } \\
\text { in cell phenotype }\end{array}$ \\
\hline
\end{tabular}

Numerous models of infection have been used to study the interaction of Burkholderia spp. with the epithelium. The location and derivation of these cell lines are shown. *Numerous cell types have now been confirmed to be contaminated with HeLa cells (cervical cancer). After original isolation the HeLa cells out compete the originally derived cell lines and dominate the cultures.

cause; melioidosis and glanders, respectively (Gilad et al., 2007). Both melioidosis and glanders can present in a range of forms and often with non-specific symptoms making early diagnosis extremely challenging (Limmathurotsakul and Peacock, 2011; Van Zandt et al., 2013). This represents a significant issue to clinicians given that, if left untreated, both diseases are associated with septic shock and high mortality rates; especially when contracted via the respiratory route. In addition, latent (chronic) infection also represents a significant issue in a clinical context by appearing to be able to reside asymptomatically within the body for years following an initial exposure. The longest recorded 
TABLE 2 | Burkholderia infection studies performed in lung epithelial cell types.

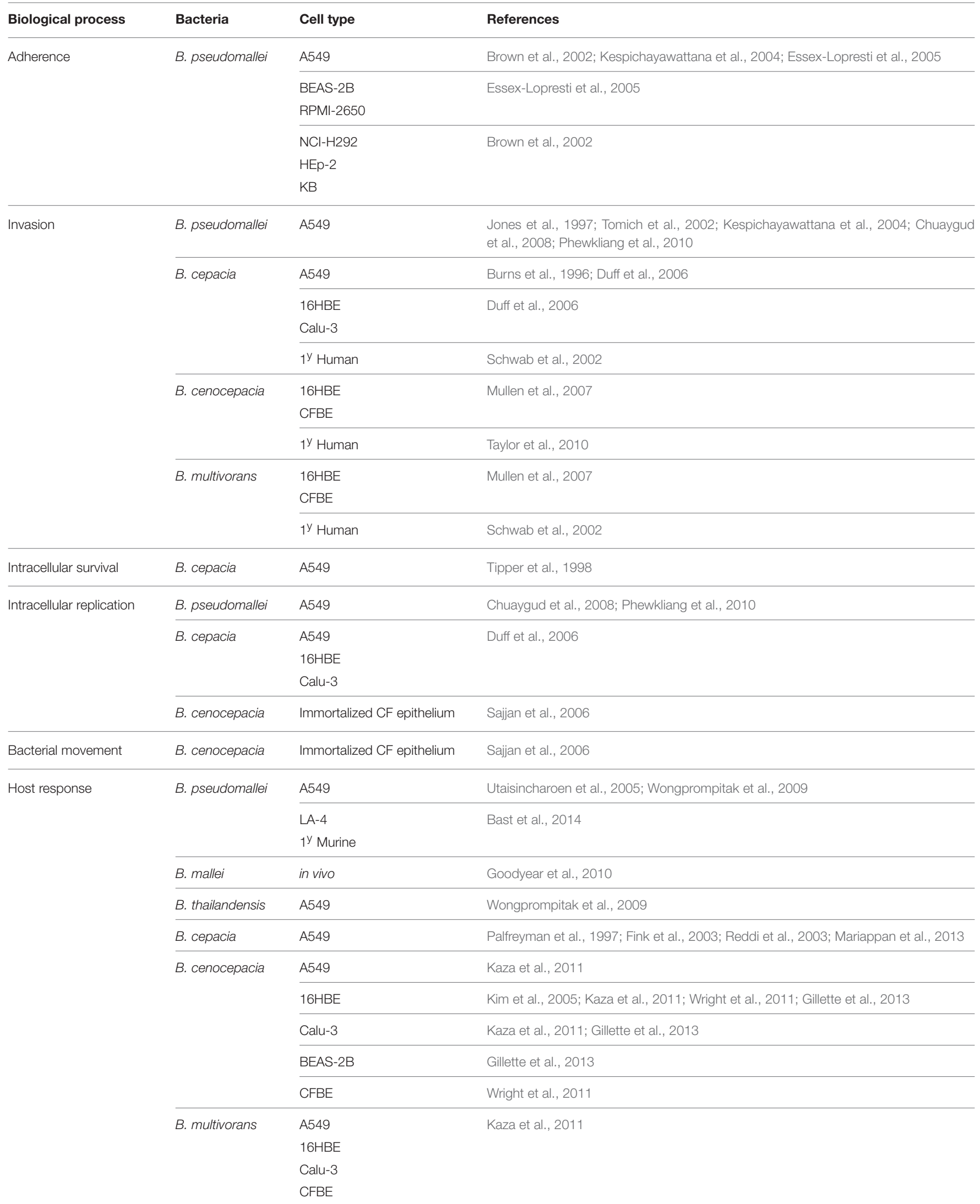


human incubation period is 62 years before clinical symptoms appeared with the bacteria remaining "dormant" during this timeframe (Ngauy et al., 2005). Disease relapse in treated patients can also recur years afterwards if the infection is not completely cleared with anti-microbial therapy (Limmathurotsakul and Peacock, 2011). The combined characteristics of acute and chronic infection make B. pseudomallei and B. mallei of particular concern from both a biodefence and public health perspective. Currently, medical therapeutic options are limited. No licensed vaccines are currently available for either melioidosis or glanders and due to natural resistance mechanisms held by the bacteria, treatment is restricted to a limited range of antibiotics. Even when treated with antibiotics mortality rates can be as high as $40 \%$ for cases of glanders (Van Zandt et al., 2013). With no licensed vaccines available antibiotic treatment remains the only option and is regularly required for many months to clear infection (Van Zandt et al., 2013). Medical guidelines currently states ceftazidime, meropenem, or imipenem with cilastatin should be used for intravenous treatment, followed by oral treatment with doxycycline and co-trimoxazole (H.C.f. Infections, 2008). Despite these prolonged antibiotic regimens, low levels of antibiotic resistance in clinical B. pseudomallei and B. mallei isolates have been observed (Heine et al., 2001; Wuthiekanun et al., 2011). However, resistance has been reported in vitro for B. mallei (Van Zandt et al., 2013), and in the clinical setting for less virulent Burkholderia spp. (Moore et al., 2001). For the successful identification of alternative treatments it is critical that the dynamic interplay between the bacteria and the host is understood. The interactions between bacteria and immune cells has previously been reviewed (Wiersinga and van der Poll, 2009; Silva and Dow, 2013) but the specific role of the lung epithelium during an infection with a Burkholderia sp. is an emerging field.

B. pseudomallei and B. mallei are highly pathogenic and therefore require Biosafety Level III containment for the safe handling and manipulation of the organism. Burkholderia thailandensis is less virulent than B. pseudomallei and is commonly used for modeling disease progression as it can be handled at lower levels of containment. Despite sharing some of these virulence mechanisms, B. thailandensis has a reduced virulence of $10^{5}$-fold in comparison to clinical B. pseudomallei strains (Brett et al., 1998). B. thailandensis has a genome with over 95\% 16S rRNA homology with $B$. pseudomallei (Brett et al., 1998). The genome also contains various homologs of $B$. pseudomallei virulence factors including components of the type III secretion systems (T3SS; Brett et al., 1998; Haraga et al., 2008). The two commonly used strains of $B$. thailandensis utilized in laboratory research are, E264 and E555. B. thailandensis E555 has greater genetic homology to $B$. pseudomallei and also, unlike E264, expresses a similar capsule (Scott et al., 2013). B. thailandensis E264 does however possess a lipopolysaccharide (LPS) with a similar carbohydrate structure to that of B. pseudomallei (Ngugi et al., 2010). The choice of $B$. thailandensis strain should therefore be driven by research aims in light of these genetic and phenotypic differences. Most other Burkholderia spp. are saprophytic organisms that are generally associated with soil or plant material however some can cause infection as opportunistic pathogens affecting immunosuppressed individuals or causing secondary infection associated with an underlying disease condition, such as cystic fibrosis (CF) (Coenye and Vandamme, 2003). These species include B. cepacia, B. cenocepacia, and B. multivorans, which form the Burkholderia cepacia complex (Bcc). B. cepacia and $B$. pseudomallei are very closely related and have previously been misidentified by some commercial diagnostic techniques (Kiratisin et al., 2007; Zong et al., 2012). Although the differences between the Bcc and the highly virulent $B$. pseudomallei and $B$. mallei are still not fully characterized, there are similarities in their life cycles. This potentially allows findings relating to the mechanism of infections used by Bcc to be correlated to those generated by more virulent bacteria strains and hence provides an insight to these diseases (Lipuma, 2005). Notably, the ability to use less virulent infection models has enabled advances in the understanding of how the Burkholderia species interact with the epithelium.

\section{Burkholderia Species: An Introduction to Virulence Factors}

Many virulence factors have been identified within pathogenic Burkholderia spp. and several of these have been shown to interact with the epithelium (Figure 1A). These interactions may offer the potential for therapeutic intervention. The best characterized example is the capsular polysaccharide which has been intensively studied for its role in disease progression and, as a consequence, has also been the focus for a number of therapeutic approaches (Reckseidler-Zenteno et al., 2009; Patel et al., 2011; Wang et al., 2011; Cuccui et al., 2012). The capsular polysaccharide aids in immune avoidance, specifically phagocytosis, and possesses homologous regions with the capsule from other respiratory pathogens including Haemophilus influenza and Neisseria meningitidis (Reckseidler et al., 2001). However, for alveolar epithelial cells (A549s) an acapsular mutant exhibited enhanced cellular internalization (Phewkliang et al., 2010). This suggests that, in this cell type at least, the capsule does not play a role in adhesion or invasion of B. pseudomallei. The secretion systems have also been identified as key virulence factors for B. pseudomallei. The genome contains six type VI secretion systems (T6SS) with cluster 1 identified as particularly important for the intracellular lifecycle of the organism (Burtnick et al., 2011). Additionally, B. pseudomallei contains three T3SS but only one has been recognized as important for virulence in humans with the other two found to have a role in plant models of infection (Haraga et al., 2008; Lee et al., 2010; D'Cruze et al., 2011). Burkholderia lethal factor 1 is a cytotoxin which has been reported to interfere with host helicase activity and aid in the process of infection (Cruz-Migoni et al., 2011). Despite $B$. mallei being considered to be a deletion clone of $B$. pseudomallei, the virulence factors from this organism are not as well characterized. $B$. mallei has a T6SS cluster that is homologous to $B$. pseudomallei but does not possess the virulence associated T3SS from B. pseudomallei (Memisevic et al., 2013). Further virulence factors (e.g., pili, flagellin) are discussed in more detail later in this review ("Adhesion and Invasion"). 


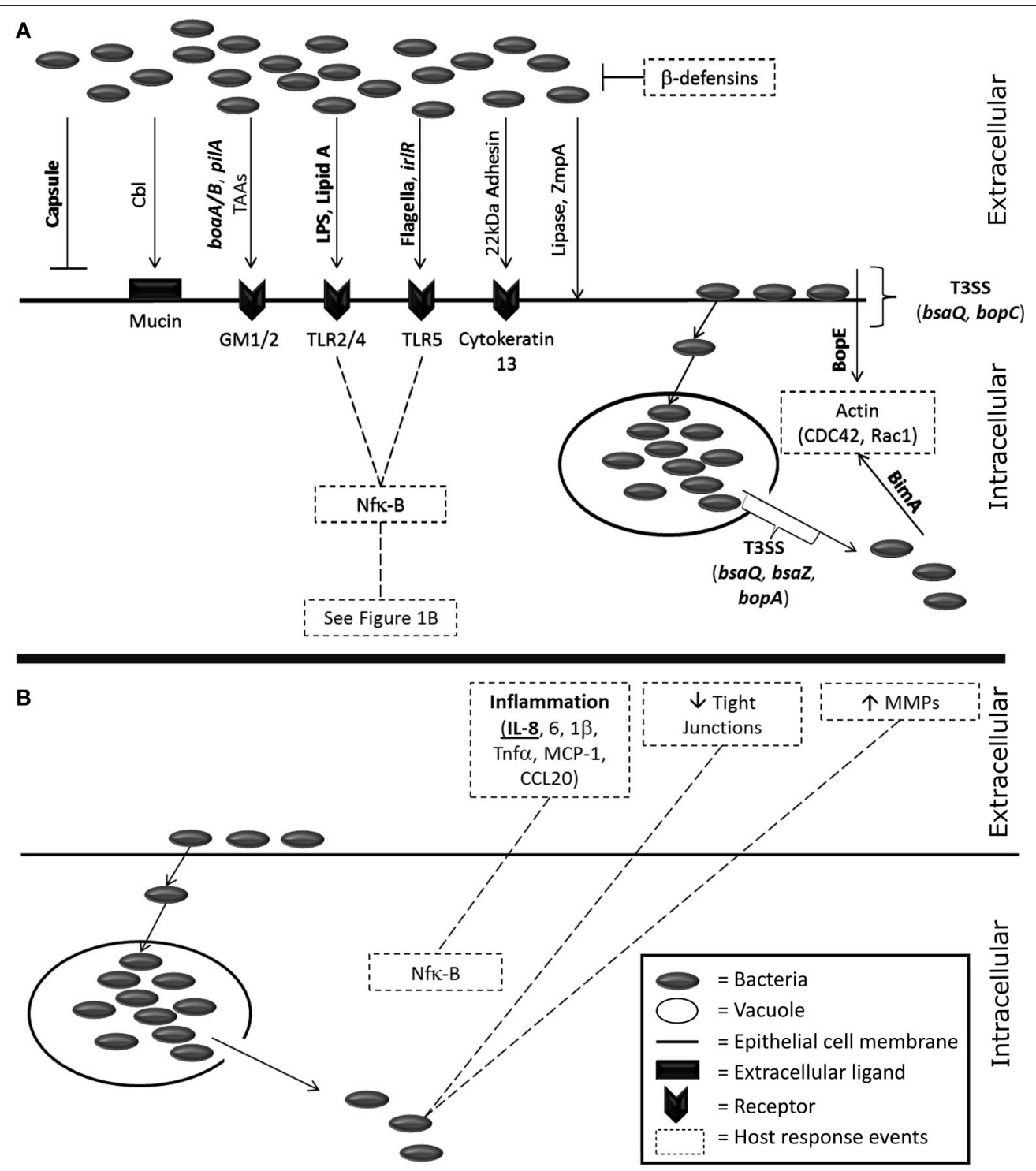

FIGURE 1 | A visualization of the known host-pathogen interactions of Burkholderia spp. with host epithelial cells. (A) Bacterial factors known to interact with host epithelial cells. Items in bold are specific for Burkholderia pseudomallei and/or mallei. Invasion of bacteria is driven by several bacterial factors; capsule (Phewkliang et al., 2010), cable pili (Sajjan and Forstner, 1992, 1993), pilA (Essex-Lopresti et al., 2005), adhesins [boaA/B (Balder et al., 2010; Lu et al., 2012) and other auto-transporter adhesins (Mil-Homens and Fialho, 2012; Lafontaine et al., 2014)], LPS (Dziarski and Gupta, 2000), Lipid A (Dziarski and Gupta, 2000), flagella (Tomich et al., 2002; Chuaygud et al., 2008; Allwood et al., 2011), irl locus (Jones et al., 1997), a 22kDa adhesion (Sajjan and Forstner, 1993), lipase (Mullen et al., 2007), and the metalloprotease ZmpA (Gingues et al., 2005). Receptor binding events on epithelial cells occur via mucin (Sajjan and Forstner, 1992), the asialogangliosides GM1/2 (Gori et al., 1999), toll-like receptors (West et al., 2009, 2013), and cytokeratin 13 (Sajjan et al., 2002). Bacterial escape from vacuoles is driven by the T3SS (Pilatz et al., 2006; Gong et al., 2011) and once the bacteria are cytosolic BimA affects host actin polymerization (Stevens et al., 2005; Sitthidet et al., 2011). Direct entry into epithelial cells has also been linked to the T3SS and the effector protein BopE which also affects host actin (Rudolph et al., 1999; Stevens et al., 2003; Muangsombut et al., 2008; Muangman et al., 2011). (B) The host response to Burkholderia infection from epithelial cells. Inflammation is driven by Nfk-B induction (Dziarski and Gupta, 2000) of IL-8 (Palfreyman et al., 1997; Fink et al., 2003; Utaisincharoen et al., 2005; Sim et al., 2009; Lu et al., 2012), IL-6 (Sim et al., 2009; Lu et al., 2012) and IL-1 (Sim et al., 2009; Lu et al., 2012; Gillette et al., 2013), TNF- $\alpha$, MCP-1 and CCL20 (Sim et al., 2009; Lu et al., 2012). Tight junctions are disrupted (Kim et al., 2005; Duff et al., 2006; Ferreira et al., 2015) and extracellular matrix components degraded by matrix metalloproteases (Wright et al., 2011).

\section{BURKHOLDERIA INFECTION OF EPITHELIAL CELLS}

Burkholderia spp. can cause disease by infecting a wide range of human cells (Stevens and Galyov, 2004; Eu et al., 2014).
There is substantial literature available on the infection of innate immune cells including macrophages, neutrophils and dendritic cells (Chieng et al., 2012; Horton et al., 2012; Bast et al., 2014). However, during an inhalational infection the pulmonary epithelial cells are one of the first cells to come 
into contact with bacteria and, along with alveolar macrophages, offer one of the first lines of defense from the organism (Dobos et al., 2000; Sim et al., 2009). The expanding interest in the epithelium as an important player in innate immunity implies that scientific research should consider the role of these cells in combating infection (Eisele and Anderson, 2011). As well as providing a physical barrier the epithelium also plays a role in innate immunity. This includes the direct effects of epithelial-derived antimicrobials such as complement, defensins, lipocalin, lysozyme, nitric oxide, and surfactant (Mason, 2006). The epithelium is also capable of recruiting a variety of immune cells including neutrophils, T- and B-cells and monocytes as well as activating immune cells via secretion of cytokines (Eisele and Anderson, 2011). Burkholderia spp. can enter the body through all areas of the respiratory system including the olfactory epithelium leading to colonization and infection of the brain (Owen et al., 2009). This specialized infection of the central nervous system by Burkholderia is reviewed elsewhere and is not the focus of this review (Dando et al., 2014). There are a variety of lung epithelial cells now available for the study of infection (Table 1). All of these models have limitations but there is a growing body of work using more complex epithelial models which are more indicative of human infection (Barrila et al., 2010; Duell et al., 2011; David et al., 2014).

\section{Adhesion and Invasion}

Adhesion and invasion of host epithelial cells are vital steps during infection appearing to contribute to the overall virulence of Burkholderia spp. For example, the in vitro infection of alveolar A549 cells by $B$. thailandensis was found to be 10 -fold lower when compared to $B$. pseudomallei. This observation was demonstrated to be due to differences between the two species ability to adhere and invade the cells and not as a consequence of intracellular survival (Kespichayawattana et al., 2004; Wongprompitak et al., 2009). Recently, the production of survival protein SurE by $B$. pseudomallei has been hypothesized to be required for invasion of cultured A549 cells suggesting a mechanism for this event (Techawiwattanaboon et al., 2015). Overall, B. pseudomallei can infect a range of epithelial cells (Brown et al., 2002), B. mallei adheres to but appears not to invade alveolar epithelial cells (Whitlock et al., 2009), whilst B. cepacia adherence and invasion is strain dependent (Keig et al., 2001, 2002; Cieri et al., 2002). This pattern also transcends into an in vivo setting as clinical isolates of B. cepacia show an eight-fold increase in adhesion and invasion of alveolar A549 cells when compared to environmental strains (Tipper et al., 1998). This highlights the importance of this stage of the infection process in determining the overall pathogenicity of the organism. Therefore, by designing treatments that can inhibit the ability of Burkholderia spp. to bind to epithelial cells may represent a potential point for therapeutic intervention in the infection cycle. This hypothesis is supported through previously published research that has demonstrated that dextran could inhibit the binding of B. cepacia to both A549s and human airway explants (Chiu et al., 2001; Sajjan et al., 2004). In these studies higher weight dextrans were found to have the greatest inhibitory effect on infection by the organism and this highlights the utility of this approach for preventing infection from $B$. cepacia.

There have been numerous studies into potential adherence factors and receptors that Burkholderia spp. may require for the initial binding event to occur with host epithelial cells. Two adhesin genes, boaA and boaB, have been identified via comparative sequence analysis due to their strong similarity to the well-characterized YadA adhesin from Yersinia enterocolitis; the first trimeric autotransporter adhesin (TAA) discovered (Casutt-Meyer et al., 2010). B. mallei express boaA whereas $B$. pseudomallei have been found to express boaB as well as boaA. It has been hypothesized that B. pseudomallei adheres more successfully to alveolar type II cells than $B$. mallei as a consequence of expressing both adherence factors ( $\mathrm{Lu}$ et al., 2012). The importance of these adhesins has further been demonstrated using knockout mutants where a B. mallei boaA knockout (ATCC23344) showed a 50\% reduction in adherence to the laryngeal derived HEp2, alveolar A549, and normal human bronchial epithelium cell lines (Balder et al., 2010). In addition by expressing boaB in recombinant Escherichia coli an increased binding to these epithelial cells was observed (Balder et al., 2010). Other TAAs have been identified in B. pseudomallei, B. mallei, and B. cenocepacia (Mil-Homens and Fialho, 2012; Lafontaine et al., 2014). For B. mallei and B. cenocepacia, mutation of the genes (BMA1027 in B. mallei and BCAM0219, 0223, and 0224 in $B$. cenocepacia) reduced the ability of the bacteria to bind to laryngeal, bronchial or alveolar human epithelial cells. However, mutation of the TAA in B. pseudomallei had no effect (Lafontaine et al., 2014). It may well be that for B. pseudomallei the adhesin role is fulfilled by boaA and boaB whereas for $B$. mallei, which only uses boaA, these other TAAs play a more important role in adhesion.

A type IV pilus gene, pilA, in B. pseudomallei, encodes a protein also involved in adhesion of the bacteria to epithelial cells. The importance of pilA has been demonstrated using the knockout pilA strain JAB16, with reduced virulence observed in both nematode worms and mice (Essex-Lopresti et al., 2005). Furthermore, the pilA mutant displayed reduced adherence to the epithelial cell lines, A549, BEAS2-B, and RPMI-2650, representing the alveoli, bronchi and nasal sections of the respiratory tract. This indicates that $B$. pseudomallei are able to bind to epithelial cells via this receptor-like mechanism ubiquitously in the respiratory tract (Essex-Lopresti et al., 2005). The specific host epithelial factors that allow bacterial adherence are predominantly unknown in B. pseudomallei and B. mallei. Asialogangliosides GM1 and GM2 are one of the few identified host receptors on pharyngeal epithelial cells facilitating B. pseudomallei attachment (Gori et al., 1999). Some Bcc species have also been shown to express proteins that act as adhesins. $B$. cepacia and B. cenocepacia express cable pili ( $\mathrm{Cbl}$ ) along with an associated $22 \mathrm{kDa}$ adhesin and their host receptors have been identified. Cbl pili allow the bacteria to attach to host mucins whilst the $22 \mathrm{kDa}$ adhesin allows binding to cytokeratin 13 on the surface of buccal host epithelial cells (Sajjan and Forstner, 1992, 1993). This means the bacteria can still attach even in the absence of mucus. This binding of B. cepacia CblA to cytokeratin 13 has been successfully blocked using anti-adhesin 
antibodies which relieved all pathological effects (Sajjan et al., 2002). The mechanism of these binding events has been studied for B. cepacia and B. cenocepacia but not for B. pseudomallei and B. mallei (Sajjan et al., 2002; Urban et al., 2005; Ganesan and Sajjan, 2011). It is likely that B. pseudomallei and B. mallei may also possess multiple adhesion-type structures in order to ensure that the organisms can mount a successful infection upon host cells under different environmental or physiological conditions. In addition, the functional pathways controlling the expression of proteins involved in adhesion are beginning to be elucidated. For example the knockout of the genes encoding the global regulators $\mathrm{BceD}$ and BceF was demonstrated to reduce the adhesion of B. contaminans to the CF epithelial cell line CFBE41o- (derived from a CF patient) by four-fold when compared to the wild-type strain (Ferreira et al., 2015). Future work to elucidate the exact mechanism with respect to how the various adhesins interact both with each other and in conjunction with host cell receptors would significantly advance our understanding of the processes involved that underpin the manifestation of disease and will, in turn, potentially facilitate therapeutic intervention at this stage of infection.

The T3SS in pathogenic Burkholderia spp. are thought to be important for host cell invasion by the injecting of a range of secretory proteins across the membrane that affect cellular functions. For example, a structural component of the secretion system is encoded for by $b s a Q$ and the production of this protein by $B$. pseudomallei can directly affect the invasion of alveolar epithelial cells (Muangsombut et al., 2008). In the absence of bsaQ B. pseudomallei invasion dropped by approximately $30 \%$ in A549 cells and the organism was unable to secrete T3SS effector proteins (e.g., BopE). The T3SS of B. pseudomallei secretes BopE which causes host cell actin rearrangement resulting in membrane ruffling aiding invasion (Stevens et al., 2003). Due to its similarity to the SopE effector protein in Salmonella it is believed that BopE functions as a guanine nucleotide exchange factor for the cell cycle regulators Cdc42 and Rac-1 and initiates actin disruption as a consequence (Rudolph et al., 1999). B. pseudomallei bopE knock out mutant strains were found to have reduced bacterial load in HeLa cells further highlighting their importance during infection (Stevens et al., 2003). More recently the effects of $B$. pseudomallei Bop family of proteins on epithelial cells have been observed where it was found that knock out bopC mutant strains had a reduced ability to invade alveolar A549 cells (Muangman et al., 2011). The role of Bop-induced actin disruption in epithelial cells requires further investigation. Some Bcc species have also been shown to induce actin disruption mirroring the observations found for the highly virulent species of Burkholderia. Burkholderia cenocepacia causes actin disruption in primary lung epithelial cells (derived from the bronchi) that had been isolated from CF patients (Sajjan et al., 2006). Burkholderia multivorans also causes a similar actin disruption in a differentiated human lung epithelial cell model (Schwab et al., 2003). For the Bcc, it has been found that the rearrangement of actin in epithelial cells is dependent upon microfilaments and microtubules (Taylor et al., 2010).

Other virulence factors thought to be involved in epithelial interactions include flagellin (DeShazer et al., 1997). The mutation of the gene encoding one structural component of the flagellum, fliC, led to a decrease in alveolar epithelial cell (A549) invasion (Chuaygud et al., 2008). The complementation of B. pseudomallei $\Delta$ fliC using the gene from both B. pseudomallei and $B$. thailandensis shows that both sources of $f l i C$ restored invasiveness. As such, flagellin does appear to be important in epithelial infection but has led others to comment that its overall role in in vivo virulence (i.e., as $B$. thailandensis is avirulent) may be minimal (Allwood et al., 2011). In B. cepacia, the mutation of gene encoding the motor-switch component of the flagellum, $f l i G$, did not affect adherence but decreased invasion in the same cell type (A549 cells). This suggests that non-functioning flagella can still bind epithelial cells but that motor function is required for infection (Tomich et al., 2002). Further, the mutation of the invasion-related locus, $\mathrm{irl}$, led to a significant reduction of $B$. pseudomallei invasion in A549 cells (10\% invasion compared to that of the wild-type; Jones et al., 1997). However, the loss of $\mathrm{irl}$ was also found to have no effect on uptake by phagocytic cell lines or in rodent studies (infant diabetic rat and Syrian hamster challenge models of infection). This suggests that, for reasons that remain unknown, these proteins are specifically required for the infection of epithelial cells.

Burkholderia spp. are also able to produce exoproducts that have been shown to affect infectivity in epithelial cells. A bacterial lipase has been identified in Bcc species capable of affecting infection in two bronchiolar epithelial cell models (Mullen et al., 2007). The inhibition of this lipase, with the lipase inhibitor Orlistat, reduced invasion rates in a dose-dependent manner and pre-treatment of the lung epithelial cells with Bcc lipase markedly increased the rate of infection (Mullen et al., 2007). Equivalent research for $B$. pseudomalle $i$ and $B$. malle $i$ has as yet not been reported.

\section{Survival, Movement and Replication}

Once inside host epithelial cells Burkholderia species reside in vacuoles where they undergo replication and prevent maturation of lysosomes and are thought to manipulate gene expression in order to slow the maturation/acidification of the endosome (Burns et al., 1996; Sajjan et al., 2006). B. pseudomallei and B. mallei in particular can circumvent the response from the host by escaping from these matured vacuoles using the T3SS (Stevens et al., 2002; Ulrich and DeShazer, 2004). BopA has been identified as a possible T3SS secreted protein that activates this vacuole escape (Gong et al., 2011). Other gene knockouts for T3SS components (e.g., bsaZ and bsaQ) have resulted in a reduced intracellular survival, in both epithelial and macrophage cell lines as a consequence of the bacteria being targeted by immune pathways whilst captured within host vacuoles (Pilatz et al., 2006; Gong et al., 2011). This demonstrates the importance of the T3SS during infection of both phagocytic and non-phagocytic cells. After vacuole escape, the bacteria can then reside in the cytoplasm and replicate en masse leading to severe pathogenesis in the host (Burns et al., 1996; Ray et al., 2009; French et al., 2011). Bacteria sequestered into autophagosomes undergo host-mediated cell destruction known as autophagy, however during severe cases of disease this is rare. B. pseudomallei has also demonstrated an 
ability to escape from these autophagosomes and hence to avoid immune responses using host actin rearrangement (Allwood et al., 2011). As well as the aforementioned role in bacterial invasion previously discussed, the manipulation of host cell actin is also regarded to be important in bacterial movement to other cells. A large amount of force can be generated by the rearrangement of the actin filaments into polymers which in turn can push the intracellular bacteria into neighboring cells spreading infection (Stevens et al., 2006). BimA has been recognized as a virulence factor produced by $B$. pseudomallei that can instigate this polymerisation event and homologs of this protein have also been identified in both $B$. mallei and $B$. thailandensis (Stevens et al., 2005; Sitthidet et al., 2011).

The mechanism of movement utilized by the highly pathogenic Burkholderia spp. in order to move across the epithelial layer has yet to be elucidated. However, some indications of the potential mechanisms that may be used exist from studying Bcc species. For example B. cenocepacia and $B$. stabilis have been previously shown to pass through cells by transcytosis and paracytosis, respectively, whilst $B$. multivorans is capable of undergoing both processes to increase intracellular spread (Schwab et al., 2002; Saldías and Valvano, 2009). There is limited supporting data to explain the underlying regulatory network that confers these specific phenotypes to the species of Burkholderia identified thus far. Although the role of a small number of bacterial derived proteins have been identified. The translocation of B. contaminans across a polarized bronchiolar epithelial cell layer is significantly decreased in the absence of the tyrosine kinase, BceF, and phosphotyrosine phosphatase, $\mathrm{BceD}$, suggesting that these proteins in some way influence translocation In addition, certain Bcc species are found to secrete metalloproteases (e.g., $\mathrm{ZmpA}$ ) in order to break down the epithelium supporting the spread of infection (Gingues et al., 2005). It is likely that highly virulent strains use a combination of these and other regulatory proteins or dissemination mechanisms and that, collectively, these contribute to the generation of acute infections. The rapidity of spread around of the body for B. pseudomallei is highlighted by colonization of other organs being noted within $24 \mathrm{~h}$ of infection during murine respiratory models of melioidosis (Lever et al., 2009; Laws et al., 2011).

\section{THE EPITHELIAL RESPONSE TO BURKHOLDERIA INFECTION}

A range of immune responses have been demonstrated to be induced following infection of epithelial cells with Burkholderia spp. (Figure 1B). Novel treatments that target these host responses (i.e., immune-modulation) offer potential opportunities for reducing bacterial pathogenesis and/or the tissue damage that occurs during an acute infection. The initial binding event of Burkholderia spp. to host cell surface receptors triggers the release of pro-inflammatory mediators. These include the activation of NFK $\beta$, Erk, and Akt pathways and induction of a vast number of cytokines such as Interleukins $1 \beta, 6$ and 8 (IL$1 \beta, 6$ and 8), tumor necrosis factor alpha (TNF- $\alpha$ ), monocyte chemotactic protein 1 (MCP-1), and chemokine(C-C motif) ligand 20 (CCL20) from alveolar and bronchiolar epithelial cells (Sim et al., 2009; Lu et al., 2012; Gillette et al., 2013). Interleukin8, a pro-inflammatory cytokine, is secreted by a variety of epithelial cell types in response to infection with a number of different Burkholderia spp. (Palfreyman et al., 1997; Reddi et al., 2003; Kaza et al., 2011; Lu et al., 2012). However, differences have been noted in the cytokines that are produced in response to infection with either B. pseudomallei or B. mallei. For example $B$. pseudomallei appears to induce a more pronounced proinflammatory response (driven by IL-6 and -8) compared to B. mallei; with the latter also previously found to produce an IL10 associated anti-inflammatory response in primary human type 2 pneumocytes (Lu et al., 2012). B. pseudomallei and B. mallei are capable of causing this IL- 8 induction by interacting with cell surface components independently of an internalization event. In the A549 alveolar model of the epithelium this activity is driven by p38 MAP kinase (Utaisincharoen et al., 2005). The toll-like receptors (TLRs) play an important role in Burkholderia infection in non-epithelial cells. Briefly, B. pseudomallei activates TLR2 and 4 on the cell surface further highlighting that the bacteria do not require internalization in order to be immunomodulatory as it was found that heat killed B. pseudomallei also induced this affect (West et al., 2008). In particular Lipid A and LPS are thought to be the key ligands for these TLRs and instigate an inflammatory cascade associated with the NFк $\beta$ pathway (Dziarski and Gupta, 2000). TLR2 activation is now thought to cause a deleterious effect on the host in response to $B$. pseudomallei infection by inducing mass inflammation and tissue damage in multiple organs (Wiersinga et al., 2007). More recently, a study has demonstrated that the flagellin of B. pseudomallei can also lead to the activation of TLR5 (West et al., 2013). Similarly, B. thailandensis has also been found to activate TLR2, 4, and 5 (West et al., 2009). The majority of research into TLR activation and the associated intracellular cascades has been performed using non-epithelial cells. However, limited evidence does exist that also indicates the importance of these receptors in tracheal, bronchiolar, and alveolar epithelial infections (Guillot et al., 2004; Kovach and Standiford, 2011; Wu et al., 2011). For example, flagellin-induced TLR5 activation has been observed during Pseudomonas aeruginosa infection of large airway primary epithelial cells (Zhang et al., 2005). Despite these findings, cell-free culture supernatants from Bcc cultures have also been able to stimulate the aforementioned IL- 8 immune response (Palfreyman et al., 1997; Fink et al., 2003). This suggests that Burkholderia spp. can stimulate an immune response via exoproducts as well as direct binding events.

The release of inflammatory mediators induces cellular recruitment in an effort to clear infection. During B. mallei infection the chemoattractant MCP-1 and TLR-activated MyD88 have been identified as particularly important for the recruitment of monocytes and dendritic cells to the site of infection. This influx causes the release of IL-12 which then recruits natural killer (NK) cells to produce interferon gamma (IFN- $\gamma$ ) driven immune cascades. The success of this initial recruitment of monocytes and dendritic cells is thought to be vital in the clearance of infection (Goodyear et al., 2010, 2012). During Bcc infection in CF patients, the influx of neutrophils to the lung epithelium 
can trigger damaging inflammation (Speert et al., 2002). In mice infected via the pulmonary route with $B$. pseudomallei, extensive neutrophil recruitment is found to occur within the alveolar spaces which is subsequently followed by mononuclear cells during the later stages of infection (West et al., 2012). An influx of immune cells can trigger further signaling pathways associated with immune clearance and inflammation. This self-perpetuating cycle can ultimately lead to the tissue damage and organ failure that is typically found in severe cases of melioidosis and glanders. Burkholderia spp. are also capable of modulating other parts of the innate immune system, such as antimicrobial peptides. Burkholderia spp. demonstrate strong resistance to these natural defense mechanisms. For example, B. pseudomallei is resistant to human alpha-defensin 1 (HNP-1) which is often a key player in bacterial clearance (Goodyear et al., 2010), whilst B. cepacia has demonstrated resistance to human beta-defensins (hBDs) 1, 2, and 3 (Speert et al., 2002; Goodyear et al., 2012).

The overall structural epithelial integrity of the lung, specifically through the loss of tight junctions and the modulation of the extracellular matrix, can also be affected following infection by Burkholderia spp. The disruption of tight junctions, following the dissociation of the main structural component occludin, has been observed in bronchial epithelial cells following infection with B. cenocepacia and B. contaminans (Kim et al., 2005; Ferreira et al., 2015). Tight junction complex disruptions have also been found to occur during the infection of A549, 16HBE, and Calu3 cells with $B$. cepacia (Duff et al., 2006). In addition, the infection of CFBE41o- cells with $B$. contaminans decreases tight junction protein 1, ZO-1, and claudin-1, as well as occludin and indicated that tight junction degradation occurs via a decrease in numerous protein components (Ferreira et al., 2015). Collectively this research highlights how widespread in nature, and therefore the potential importance of, tight junction disruption is in aiding the development of an infectious disease. This will ultimately contribute to the loss of epithelial integrity in the lungs that has now been observed for several species of Burkholderia and is hypothesized that this aids in the dissemination of the infection. A continued breakdown of the lung epithelia is also thought to occur following the up-regulation of host matrix metalloproteinase (MMP) expression in response to infection with Burkholderia spp. In particular the gelatinases MMP-2 and MMP-9, which breakdown collagen and other extracellular matrix components, have been shown to be up-regulated in vitro following infection with B. cenocepacia (Wright et al., 2011). Clearly the damage that would be caused to the lung epithelium during infection would allow for extensive bacterial spread into the circulatory systems and therefore contribute to the severity of the disease.

Transcriptomics has been used by several groups to look at the global mRNA changes in response to Burkholderia infection in a variety of models and tissues, including blood, liver, and spleen (Pankla et al., 2009; Chin et al., 2010, 2012; Conejero et al., 2015). A recent microarray study of alveolar A549 cells infected with $B$. cepacia identified that the host genes involved in inflammation, apoptosis, and the cell cycle were all downregulated (Mariappan et al., 2013). By dampening the immune responses and by preventing apoptosis virulent Burkholderia strains can create a beneficial environment for replication and survival. Transcriptomics on epithelial cells have yet to be carried out for $B$. mallei but have been used by some groups for B. pseudomallei (Wongprompitak et al., 2009). The host response in whole tissue homogenates has also been studied for B. pseudomallei (Ulett et al., 2005; Conejero et al., 2015). Unsurprisingly, the response identified numerous immune and inflammatory genes changing in expression (e.g., IL-1, 4, and 15, TNF related genes). Despite the overwhelming immune responses that were induced it has also been possible to elucidate the specific involvement of the epithelia during infection from in vivo lung homogenates (David et al., 2012). This suggests that mechanistic studies to derive epithelial host-pathogen interactions would benefit from "in vivo-like" co-culture models (Barrila et al., 2010; Duell et al., 2011). Coupling transcriptomics with more complex three dimensional cell models of infection (creating a more "in-vivo-like" lung environment) has been utilized successfully to investigate host-pathogen interactions for other bacteria (David et al., 2014). More advanced approaches of this type may aid in the discovery of new targets for therapeutic intervention in the future.

\section{CONCLUDING REMARKS}

The diseases melioidosis and glanders caused by B. pseudomallei and $B$. mallei, respectively, are an enduring issue of international concern. At present the treatments available are limited, protracted and largely ineffective. As a consequence, new approaches are required in order to identify new drugs or drug targets that aid in the clearance of infection. It is clear that the interaction between pathogenic Burkholderia spp. and the epithelium is a key determinant in virulence. The interactions between these organisms and the lung epithelium represents an under researched area, which may offer the potential for new therapeutic interventions. Innovations in the field of opportunistic pathogens for the treatment of CF may yield transferable models, drugs or drug targets that could be utilized in order to identify efficacious treatments against infections caused by the highly virulent strains of $B$. pseudomallei and B. mallei.

\section{AUTHOR CONTRIBUTIONS}

$\mathrm{JD}$ and $\mathrm{RB}$ reviewed the data from the literature and organized and wrote the manuscript. GC was involved in writing and editing the final version of the manuscript. All of the authors read and approved the final version of the manuscript.

\section{ACKNOWLEDGMENTS}

This work was funded by the UK Ministry of Defence. 


\section{REFERENCES}

Allwood, E. M., Devenish, R. J., Prescott, M., Adler, B., and Boyce, J. D. (2011). Strategies for intracellular survival of Burkholderia pseudomallei. Front. Microbiol. 2:170. doi: 10.3389/fmicb.2011.00170

Balder, R., Lipski, S., Lazarus, J. J., Grose, W., Wooten, R. M., Hogan, R. J., et al. (2010). Identification of Burkholderia mallei and Burkholderia pseudomallei adhesins for human respiratory epithelial cells. BMC Microbiol. 10:250. doi: 10.1186/1471-2180-10-250

Barrila, J., Radtke, A. L., Crabbé, A., Sarker, S. F., Herbst-Kralovetz, M. M., Ott, C. M., et al. (2010). Organotypic 3d cell culture models: using the rotating wall vessel to study host-pathogen interactions. Nat. Rev. Microbiol. 8, 791-801. doi: $10.1038 /$ nrmicro2423

Bast, A., Krause, K., Schmidt, I. H., Pudla, M., Brakopp, S., Hopf, V., et al. (2014). Caspase-1-dependent and -independent cell death pathways in Burkholderia pseudomallei infection of macrophages. PLoS Pathog. 10:e1003986. doi: 10.1371/journal.ppat.1003986

Brett, P. J., DeShazer, D., and Woods, D. E. (1998). Burkholderia thailandensis sp. Nov., a Burkholderia pseudomallei-like species. Int. J. Syst. Bacteriol. 48(Pt 1), 317-320. doi: 10.1099/00207713-48-1-317

Brown, N. F., Boddey, J. A., Flegg, C. P., and Beacham, I. R. (2002). Adherence of Burkholderia pseudomallei cells to cultured human epithelial cell lines is regulated by growth temperature. Infect. Immun. 70, 974-980. doi: 10.1128/IAI.70.2.974-980.2002

Burns, J. L., Jonas, M., Chi, E. Y., Clark, D. K., Berger, A., and Griffith, A. (1996). Invasion of respiratory epithelial cells by burkholderia (pseudomonas) cepacia. Infect. Immun. 64, 4054-4059.

Burtnick, M. N., Brett, P. J., Harding, S. V., Ngugi, S. A., Ribot, W. J., Chantratita, N., et al. (2011). The cluster 1 type vi secretion system is a major virulence determinant in Burkholderia pseudomallei. Infect. Immun. 79, 1512-1525. doi: 10.1128/iai.01218-10

Carney, D. N., Gazdar, A. F., Bepler, G., Guccion, J. G., Marangos, P. J., Moody, T. W., et al. (1985). Establishment and identification of small cell lung-cancer cell-lines having classic and variant features. Cancer Res. 45, 2913-2923.

Casutt-Meyer, S., Renzi, F., Schmaler, M., Jann, N. J., Amstutz, M., and Cornelis, G. R. (2010). Oligomeric coiled-coil adhesin yada is a double-edged sword. PLoS ONE 5:e15159. doi: 10.1371/journal.pone.0015159

Chen, T. R. (1988). Re-evaluation of hela, hela s3, and hep-2 karyotypes. Cytogenet. Cell Genet. 48, 19-24. doi: 10.1159/000132579

Chieng, S., Carreto, L., and Nathan, S. (2012). Burkholderia pseudomallei transcriptional adaptation in macrophages. BMC Genomics 13:328. doi: 10.1186/1471-2164-13-328

Chin, C.-Y., Monack, D. M., and Nathan, S. (2010). Genome wide transcriptome profiling of a murine acute melioidosis model reveals new insights into how Burkholderia pseudomallei overcomes host innate immunity. BMC Genomics 11:672. doi: 10.1186/1471-2164-11-672

Chin, C.-Y., Monack, D. M., and Nathan, S. (2012). Delayed activation of host innate immune pathways in streptozotocin-induced diabetic hosts leads to more severe disease during infection with Burkholderia pseudomallei. Immunology 135, 312-332. doi: 10.1111/j.1365-2567.2011.03544.x

Chiu, C. H., Wong, S., Hancock, R. E., and Speert, D. P. (2001). Adherence of Burkholderia cepacia to respiratory tract epithelial cells and inhibition with dextrans. Microbiology 147, 2651-2658. doi: 10.1099/00221287-147-10-2651

Chuaygud, T., Tungpradabkul, S., Sirisinha, S., Chua, K. L., and Utaisincharoen, P. (2008). A role of Burkholderia pseudomallei flagella as a virulent factor. Trans. R. Soc. Trop. Med. Hyg. 102(Suppl. 1), S140-S144. doi: 10.1016/j.trstmh.2008.08.025

Cieri, M. V., Mayer-Hamblett, N., Griffith, A., and Burns, J. L. (2002). Correlation between an in vitro invasion assay and a murine model of Burkholderia cepacia lung infection. Infect. Immun. 70, 1081-1086. doi: 10.1128/IAI.70.3.10811086.2002

Coenye, T., and Vandamme, P. (2003). Diversity and significance of burkholderia species occupying diverse ecological niches. Environ. Microbiol. 5, 719-729. doi: 10.1046/j.1462-2920.2003.00471.x

Conejero, L., Potempa, K., Graham, C. M., Spink, N., Blankley, S., Salguero, F. J., et al. (2015). The blood transcriptome of experimental melioidosis reflects disease severity and shows considerable similarity with the human disease. J. Immunol. 195, 3248-3261. doi: 10.4049/jimmunol.1500641
Cozens, A. L., Yezzi, M. J., Kunzelmann, K., Ohrui, T., Chin, L., Eng, K., et al. (1994). Cftr expression and chloride secretion in polarized immortal human bronchial epithelial-cells. Am. J. Respir. Cell Mol. Biol. 10, 38-47. doi: 10.1165/ajrcmb.10.1.7507342

Cruz-Migoni, A., Hautbergue, G. M., Artymiuk, P. J., Baker, P. J., BokoriBrown, M., Chang, C. T., et al. (2011). A Burkholderia pseudomallei toxin inhibits helicase activity of translation factor eif4a. Science 334, 821-824. doi: 10.1126/science. 1211915

Cuccui, J., Milne, T. S., Harmer, N., George, A. J., Harding, S. V., Dean, R. E., et al. (2012). Characterization of the Burkholderia pseudomallei k96243 capsular polysaccharide i coding region. Infect. Immun. 80, 1209-1221. doi: 10.1128/IAI.05805-11

D’Cruze, T., Gong, L., Treerat, P., Ramm, G., Boyce, J. D., Prescott, M., et al. (2011). Role for the Burkholderia pseudomallei type three secretion system cluster 1 bpscn gene in virulence. Infect. Immun. 79, 3659-3664. doi: 10.1128/IAI.0135110

Dando, S. J., Mackay-Sim, A., Norton, R., Currie, B. J., St John, J. A., Ekberg, J. A. K., et al. (2014). Pathogens penetrating the central nervous system: infection pathways and the cellular and molecular mechanisms of invasion. Clin. Microbiol. Rev. 27, 691-726. doi: 10.1128/CMR.00118-13

David, J., Gates, A. J., Griffiths, G. D., and Lukaszewski, R. A. (2012). Gene expression following low dose inhalational Francisella tularensis (schus4) exposure in balb/c mice and the potential role of the epithelium and cell adhesion. Microb. Infect. 14, 369-379. doi: 10.1016/j.micinf.2011. 11.006

David, J., Sayer, N. M., and Sarkar-Tyson, M. (2014).The use of a three-dimensional cell culture model to investigate host-pathogen interactions of Francisella tularensis in human lung epithelial cells. Microb. Infect. 16, 735-745. doi: 10.1016/j.micinf.2014.04.001

DeShazer, D., Brett, P. J., Carlyon, R., and Woods, D. E. (1997). Mutagenesis of Burkholderia pseudomallei with tn5-ot182: isolation of motility mutants and molecular characterization of the flagellin structural gene. J. Bacteriol. 179, 2116-2125.

Dobos, K. M., Spotts, E. A., Quinn, F. D., and King, C. H. (2000). Necrosis of lung epithelial cells during infection with mycobacterium tuberculosis is preceded by cell permeation. Infect. Immun. 68, 6300-6310. doi: 10.1128/IAI.68.11.63006310.2000

Duell, B. L., Cripps, A. W., Schembri, M. A., and Ulett, G. C. (2011). Epithelial cell coculture models for studying infectious diseases: benefits and limitations. J. Biomed. Biotechnol. 2011:852419. doi: 10.1155/2011/852419

Duff, C., Murphy, P. G., Callaghan, M., and McClean, S. (2006). Differences in invasion and translocation of Burkholderia cepacia complex species in polarised lung epithelial cells in vitro. Microb. Pathog. 41, 183-192. doi: 10.1016/j.micpath.2006.07.005

Dziarski, R., and Gupta, D. (2000). Role of md-2 in tlr2- and tlr4mediated recognition of gram-negative and gram-positive bacteria and activation of chemokine genes. J. Endotoxin Res. 6, 401-405. doi: $10.1177 / 09680519000060050101$

Eagle, H., Habel, K., Rowe, W. P., and Huebner, R. J. (1956). Viral susceptibility of a human carcinoma cell (strain-kb). Proc. Soc. Exp. Biol. Med. 91, 361-364. doi: 10.3181/00379727-91-22263

Eisele, N. A., and Anderson, D. M. (2011). Host defense and the airway epithelium: frontline responses that protect against bacterial invasion and pneumonia. J. Pathog. 2011:249802. doi: 10.4061/2011/249802

Essex-Lopresti, A. E., Boddey, J. A., Thomas, R., Smith, M. P., Hartley, M. G. Atkins, T., et al. (2005). A type iv pilin, pila, contributes to adherence of Burkholderia pseudomallei and virulence in vivo. Infect. Immun. 73, 1260-1264. doi: 10.1128/IAI.73.2.1260-1264.2005

Eu, L. C., Ong, K. C., Hiu, J., Vadivelu, J., Nathan, S., and Wong, K. T. (2014). In situ hybridization to detect and identify Burkholderia pseudomallei in human melioidosis. Mod. Pathol. 27, 657-664. doi: 10.1038/modpathol.2013.184

Ferreira, A. S., Silva, I. N., Fernandes, F., Pilkington, R., Callaghan, M., McClean, S., et al. (2015). The tyrosine kinase bcef and the phosphotyrosine phosphatase bced of burkholderia contaminans are required for efficient invasion and epithelial disruption of a cystic fibrosis lung epithelial cell line. Infect. Immun. 83, 812-821. doi: 10.1128/IAI.02713-14

Fink, J., Steer, J. H., Joyce, D. A., McWilliam, A. S., and Stewart, G. A. (2003). Pro-inflammatory effects of Burkholderia cepacia on cystic fibrosis respiratory 
epithelium. FEMS Immunol. Med. Microbiol. 38, 273-282. doi: 10.1016/S09288244(03)00169-X

Fogh, J., Wright, W. C., and Loveless, J. D. (1977). Absence of hela-cell contamination in 169 cell lines derived from human tumors. J. Natl. Cancer Inst. 58, 209-214.

French, C. T., Toesca, I. J., Wu, T.-H., Teslaa, T., Beaty, S. M., Wong, W., et al. (2011). Dissection of the burkholderia intracellular life cycle using a photothermal nanoblade. Proc. Natl. Acad. Sci. U.S.A. 108, 12095-12100. doi: $10.1073 /$ pnas. 1107183108

Ganesan, S., and Sajjan, U. S. (2011). Host evasion by Burkholderia cenocepacia. Front. Cell. Infect. Microbiol. 1:25. doi: 10.3389/fcimb.2011.00025

Gilad, J., Harary, I., Dushnitsky, T., Schwartz, D., and Amsalem, Y. (2007), Burkholderia mallei and Burkholderia pseudomallei as bioterrorism agents: National aspects of emergency preparedness. Isr. Med. Assoc. J. 9, 499-503.

Gillette, D. D., Shah, P. A., Cremer, T., Gavrilin, M. A., Besecker, B. Y., Sarkar, A., et al. (2013). Analysis of human bronchial epithelial cell proinflammatory response to Burkholderia cenocepacia infection: inability to secrete il-1beta. J. Biol. Chem. 288, 3691-3695. doi: 10.1074/jbc.c112.430298

Gingues, S., Kooi, C., Visser, M. B., Subsin, B., and Sokol, P. A. (2005). Distribution and expression of the zmpa metalloprotease in the Burkholderia cepacia complex. J. Bacteriol. 187, 8247-8255. doi: 10.1128/JB.187.24.82478255.2005

Gong, L., Cullinane, M., Treerat, P., Ramm, G., Prescott, M., Adler, B., et al. (2011). The Burkholderia pseudomallei type iii secretion system and bopa are required for evasion of lc3-associated phagocytosis. PLOS ONE 6:e17852. doi: 10.1371/journal.pone.0017852

Goodyear, A., Jones, A., Troyer, R., Bielefeldt-Ohmann, H., and Dow, S. (2010). Critical protective role for mcp-1 in pneumonic Burkholderia mallei infection. J. Immunol. 184, 1445-1454. doi: 10.4049/jimmunol.0900411

Goodyear, A., Troyer, R., Bielefeldt-Ohmann, H., and Dow, S. (2012). Myd88dependent recruitment of monocytes and dendritic cells required for protection from pulmonary Burkholderia mallei infection. Infect. Immun. 80, 110-120. doi: 10.1128/IAI.05819-11

Gori, A. H., Ahmed, K., Martinez, G., Masaki, H., Watanabe, K., and Nagatake, T. (1999). Mediation of attachment of Burkholderia pseudomallei to human pharyngeal epithelial cells by the asialoganglioside gm1-gm 2 receptor complex. Am. J. Trop. Med. Hyg. 61, 473-475.

Guillot, L., Medjane, S., Le-Barillec, K., Balloy, V., Danel, C., Chignard, M., et al. (2004). Response of human pulmonary epithelial cells to lipopolysaccharide involves toll-like receptor 4 (tlr4)-dependent signaling pathways: evidence for an intracellular compartmentalization of tlr4. J. Biol. Chem. 279, 2712-2718. doi: 10.1074/jbc.M305790200

H.C.f. Infections (2008). Guidelines for Action in the Event of a Deliberate Release: Glanders and Melioidosis, Version 3.3. London: HPA Centre for Infections. Available online at: http://webarchive.nationalarchives.gov.uk/ 20140714084352/http://www.hpa.org.uk/webc/HPAwebFile/HPAweb_C/119 4947412449

Haraga, A., West, T. E., Brittnacher, M. J., Skerrett, S. J., and Miller, S. I. (2008). Burkholderia thailandensis as a model system for the study of the virulence-associated type iii secretion system of Burkholderia pseudomallei. Infect. Immun. 76, 5402-5411. doi: 10.1128/IAI. 00626-08

Heine, H. S., England, M. J., Waag, D. M., and Byrne, W. R. (2001). In vitro antibiotic susceptibilities of Burkholderia mallei (causative agent of glanders) determined by broth microdilution and e-test. Antimicrob. Agents Chemother. 45, 2119-2121. doi: 10.1128/AAC.45.7.2119-2121.2001

Horton, R. E., Morrison, N. A., Beacham, I. R., and Peak, I. R. (2012). Interaction of Burkholderia pseudomallei and Burkholderia thailandensis with human monocyte-derived dendritic cells. J. Med. Microbiol. 61, 607-614. doi: 10.1099/jmm.0.038588-0

Jones, A. L., DeShazer, D., and Woods, D. E. (1997). Identification and characterization of a two-component regulatory system involved in invasion of eukaryotic cells and heavy-metal resistance in Burkholderia pseudomallei. Infect. Immun. 65, 4972-4977.

Kaza, S. K., McClean, S., and Callaghan, M. (2011). Il-8 released from human lung epithelial cells induced by cystic fibrosis pathogens Burkholderia cepacia complex affects the growth and intracellular survival of bacteria. Int. J. Med. Microbiol. 301, 26-33. doi: 10.1016/j.ijmm.2010.06.005
Keig, P. M., Ingham, E., and Kerr, K. G. (2001). Invasion of human type ii pneumocytes by Burkholderia cepacia. Microb. Pathog. 30, 167-170. doi: $10.1006 /$ mpat.2000.0418

Keig, P. M., Ingham, E., Vandamme, P. A., and Kerr, K. G. (2002). Differential invasion of respiratory epithelial cells by members of the Burkholderia cepacia complex. Clin. Microbiol. Infect. 8, 47-49. doi: 10.1046/j.14690691.2002.00356.x

Kespichayawattana, W., Intachote, P., Utaisincharoen, P., and Sirisinha, S. (2004). Virulent Burkholderia pseudomallei is more efficient than avirulent Burkholderia thailandensis in invasion of and adherence to cultured human epithelial cells. Microb. Pathog. 36, 287-292. doi: 10.1016/j.micpath.2004.01.001

Kim, J. Y., Sajjan, U. S., Krasan, G. P., and LiPuma, J. J. (2005). Disruption of tight junctions during traversal of the respiratory epithelium by Burkholderia cenocepacia. Infect. Immun. 73, 7107-7112. doi: 10.1128/IAI.73.11.71077112.2005

Kiratisin, P., Santanirand, P., Chantratita, N., and Kaewdaeng, S. (2007). Accuracy of commercial systems for identification of Burkholderia pseudomallei versus Burkholderia cepacia. Diagn. Microbiol. Infect. Dis. 59, 277-281. doi: 10.1016/j.diagmicrobio.2007.06.013

Kovach, M. A., and Standiford, T. J. (2011). Toll like receptors in diseases of the lung. Int. Immunopharmacol. 11, 1399-1406. doi: 10.1016/j.intimp.2011.05.013

Lafontaine, E. R., Balder, R., Michel, F., and Hogan, R. J. (2014). Characterization of an autotransporter adhesin protein shared by Burkholderia mallei and Burkholderia pseudomallei. BMC Microbiol. 14:92. doi: 10.1186/1471-2180$14-92$

Laws, T. R., Smither, S. J., Lukaszewski, R. A., and Atkins, H. S. (2011). Neutrophils are the predominant cell-type to associate with Burkholderia pseudomallei in a balb/c mouse model of respiratory melioidosis. Microb. Pathog. 51, 471-475. doi: 10.1016/j.micpath.2011.07.002

Lee, Y. H., Chen, Y., Ouyang, X., and Gan, Y.-H. (2010). Identification of tomato plant as a novel host model for Burkholderia pseudomallei. BMC Microbiol. 10:28. doi: 10.1186/1471-2180-10-28

Lever, M. S., Nelson, M., Stagg, A. J., Beedham, R. J., and Simpson, A. J. H. (2009). Experimental acute respiratory Burkholderia pseudomallei infection in balb/c mice. Int. J. Exp. Pathol. 90, 16-25. doi: 10.1111/j.1365-2613.2008.00619.x

Lieber, M., Smith, B., Szakal, A., Nelson-Rees, W., and Todaro, G. (1976). Continuous tumor-cell line from a human lung carcinoma with properties of type-ii alveolar epithelial cells. Int. J. Cancer 17, 62-70. doi: 10.1002/ijc.2910170110

Limmathurotsakul, D., and Peacock, S. J. (2011). Melioidosis: a clinical overview. Br. Med. Bull. 99, 125-139. doi: 10.1093/bmb/ldr007

Lipuma, J. J. (2005). Update on the Burkholderia cepacia complex. Curr. Opin. Pulm. Med. 11, 528-533. doi: 10.1097/01.mcp.0000181475.85187.ed

Lu, R., Popov, V., Patel, J., and Eaves-Pyles, T. (2012). Burkholderia mallei and Burkholderia pseudomallei stimulate differential inflammatory responses from human alveolar type ii cells (atii) and macrophages. Front. Cell. Infect. Microbiol. 2:165. doi: 10.3389/fcimb.2012.00165

Mariappan, V., Vellasamy, K. M., Thimma, J., Hashim, O. H., and Vadivelu, J. (2013). Infection of Burkholderia cepacia induces homeostatic responses in the host for their prolonged survival: the microarray perspective. PLOS ONE 8:e77418. doi: 10.1371/journal.pone.0077418

Mason, R. J. (2006). Biology of alveolar type ii cells. Respirology 11, S12-S15. doi: 10.1111/j.1440-1843.2006.00800.x

Memisevic, V., Zavaljevski, N., Pieper, R., Rajagopala, S. V., Kwon, K., Townsend, K., et al. (2013). Novel Burkholderia mallei virulence factors linked to specific host-pathogen protein interactions. Mol. Cell. Proteom. 12, 3036-3051. doi: 10.1074/mcp.M113.029041

Mil-Homens, D., and Fialho, A. M. (2012). A bcam0223 mutant of Burkholderia cenocepacia is deficient in hemagglutination, serum resistance, adhesion to epithelial cells and virulence. PLOS ONE 7:e41747. doi: 10.1371/journal.pone.0041747

Moore, J. E., Crowe, M., Shaw, A., McCaughan, J., Redmond, A. O., and Elborn, J. S. (2001). Antibiotic resistance in Burkholderia cepacia at two regional cystic fibrosis centres in northern ireland: is there a need for synergy testing? J. Antimicrob. Chemother. 48, 319-321. doi: 10.1093/jac/48.2.319

Moorhead, P. S. (1965). Human tumor cell line with a quasi-diploid karyotype (RPMI 2650). Exp. Cell Res. 39, 190-196. doi: 10.1016/0014-4827(65) 90022-4 
Muangman, S., Korbsrisate, S., Muangsombut, V., Srinon, V., Adler, N. L., Schroeder, G. N., et al. (2011). Bopc is a type iii secreted effector protein of Burkholderia pseudomallei. FEMS Microbiol. Lett. 323, 75-82. doi: 10.1111/j.1574-6968.2011.02359.x

Muangsombut, V., Suparak, S., Pumirat, P., Damnin, S., Vattanaviboon, P., Thongboonkerd, V., et al. (2008). Inactivation of Burkholderia pseudomallei bsaq results in decreased invasion efficiency and delayed escape of bacteria from endocytic vesicles. Arch. Microbiol. 190, 623-631. doi: 10.1007/s00203008-0413-3

Mullen, T., Markey, K., Murphy, P., McClean, S., and Callaghan, M. (2007). Role of lipase in Burkholderia cepacia complex (bcc) invasion of lung epithelial cells. Eur. J. Clin. Microbiol. Infect. Dis. 26, 869-877. doi: 10.1007/s10096-007-0385-2

Ngauy, V., Lemeshev, Y., Sadkowski, L., and Crawford, G. (2005). Cutaneous melioidosis in a man who was taken as a prisoner of war by the japanese during world war ii. J. Clin. Microbiol. 43, 970-972. doi: 10.1128/JCM.43.2.970972.2005

Ngugi, S. A., Ventura, V. V., Qazi, O., Harding, S. V., Kitto, G. B., Estes, D. M., et al. (2010). Lipopolysaccharide from Burkholderia thailandensis e264 provides protection in a murine model of melioidosis. Vaccine 28, 7551-7555. doi: 10.1016/j.vaccine.2010.08.058

Owen, S. J., Batzloff, M., Chehrehasa, F., Meedeniya, A., Casart, Y., Logue C.A., et al. (2009). Nasal-associated lymphoid tissue and olfactory epithelium as portals of entry for Burkholderia pseudomallei in murine melioidosis. J. Infect. Dis. 199, 1761-1770. doi: 10.1086/599210

Palfreyman, R. W., Watson, M. L., Eden, C., and Smith, A. W. (1997). Induction of biologically active interleukin- 8 from lung epithelial cells by burkholderia (pseudomonas) cepacia products. Infect. Immun. 65, 617-622.

Pankla, R., Buddhisa, S., Berry, M., Blankenship, D. M., Bancroft, G. J., Banchereau, J., et al. (2009). Genomic transcriptional profiling identifies a candidate blood biomarker signature for the diagnosis of septicemic melioidosis. Genome Biol. 10, R127.1-R127.22. doi: 10.1186/gb-2009-10-11-r127

Parker, D., and Prince, A. (2011). Innate immunity in the respiratory epithelium. Am. J. Respir. Cell Mol. Biol. 45, 189-201. doi: 10.1165/rcmb.2011-0011RT

Patel, N., Conejero, L., De Reynal, M., Easton, A., Bancroft, G. J., and Titball, R. W. (2011). Development of vaccines against Burkholderia pseudomallei. Front. Microbiol. 2:198. doi: 10.3389/fmicb.2011.00198

Phewkliang, A., Wongratanacheewin, S., and Chareonsudjai, S. (2010). Role of Burkholderia pseudomallei in the invasion, replication and induction of apoptosis in human epithelial cell lines. Southeast Asian J. Trop. Med. Public Health 41, 1164-1176.

Pilatz, S., Breitbach, K., Hein, N., Fehlhaber, B., Schulze, J., Brenneke, B., et al. (2006). Identification of Burkholderia pseudomallei genes required for the intracellular life cycle and in vivo virulence. Infect. Immun. 74, 3576-3586. doi: 10.1128/iai.01262-05

Ray, K., Marteyn, B., Sansonetti, P. J., and Tang, C. M. (2009). Life on the inside: the intracellular lifestyle of cytosolic bacteria. Nat. Rev. Microbiol. 7, 333-340. doi: $10.1038 /$ nrmicro2112

Reckseidler, S. L., DeShazer, D., Sokol, P. A., and Woods, D. E. (2001). Detection of bacterial virulence genes by subtractive hybridization: identification of capsular polysaccharide of Burkholderia pseudomallei as a major virulence determinant. Infect. Immun. 69, 34-44. doi: 10.1128/IAI.69.1.34-44.2001

Reckseidler-Zenteno, S. L., Moore, R., and Woods, D. E. (2009). Genetics and function of the capsules of Burkholderia pseudomallei and their potential as therapeutic targets. Mini Rev. Med. Chem. 9, 265-271. doi: $10.2174 / 138955709787316047$

Reddel, R. R., Ke, Y., Gerwin, B. I., McMenamin, M. G., Lechner, J. F., Su, R. T., et al. (1988). Transformation of human bronchial epithelial-cells by infection with sv40 or adenovirus-12 sv40 hybrid virus, or transfection via strontium phosphate coprecipitation with a plasmid containing sv40 early region genes. Cancer Res. 48, 1904-1909.

Reddi, K., Phagoo, S. B., Anderson, K. D., and Warburton, D. (2003). Burkholderia cepacia -induced il-8 gene expression in an alveolar epithelial cell line: Signaling through cd14 and mitogen-activated protein kinase. Pediatr. Res. 54, 297-305. doi: 10.1203/01.PDR.0000076661.85928.1D

Rudolph, M. G., Weise, C., Mirold, S., Hillenbrand, B., Bader, B., Wittinghofer, A., et al. (1999). Biochemical analysis of sope from salmonella typhimurium, a highly efficient guanosine nucleotide exchange factor for rhogtpases. J. Biol. Chem. 274, 30501-30509. doi: 10.1074/jbc.274.43.30501
Sajjan, S. U., and Forstner, J. F. (1992). Identification of the mucin-binding adhesin of pseudomonas cepacia isolated from patients with cystic fibrosis. Infect. Immun. 60, 1434-1440.

Sajjan, U., Ackerley, C., and Forstner, J. (2002). Interaction of cbla/adhesin-positive Burkholderia cepacia with squamous epithelium. Cell. Microbiol. 4, 73-86. doi: 10.1046/j.1462-5822.2002.00171.x

Sajjan, U., Moreira, J., Liu, M., Humar, A., Chaparro, C., Forstner, J., et al. (2004). A novel model to study bacterial adherence to the transplanted airway: Inhibition of Burkholderia cepacia adherence to human airway by dextran and xylitol J. Heart Lung Transplant. 23, 1382-1391. doi: 10.1016/j.healun.2003.09.023

Sajjan, U. S., and Forstner, J. F. (1993). Role of a 22-kilodalton pilin protein in binding of pseudomonas cepacia to buccal epithelial cells. Infect. Immun. 61, 3157-3163.

Sajjan, U. S., Yang, J. H., Hershenson, M. B., and LiPuma, J. J. (2006). Intracellular trafficking and replication of Burkholderia cenocepacia in human cystic fibrosis airway epithelial cells. Cell. Microbiol. 8, 1456-1466. doi: 10.1111/j.14625822.2006.00724.x

Saldías, M. S., and Valvano, M. A. (2009). Interactions of Burkholderia cenocepacia and other Burkholderia cepacia complex bacteria with epithelial and phagocytic cells. Microbiology 155, 2809-2817. doi: 10.1099/mic.0.031344-0

Schwab, U. E., Ribeiro, C. M., Neubauer, H., and Boucher, R. C. (2003). Role of actin filament network in Burkholderia multivorans invasion in welldifferentiated human airway epithelia. Infect. Immun. 71, 6607-6609. doi: 10.1128/IAI.71.11.6607-6609.2003

Schwab, U., Leigh, M., Ribeiro, C., Yankaskas, J., Burns, K., Gilligan, P., et al. (2002). Patterns of epithelial cell invasion by different species of the Burkholderia cepacia complex in well-differentiated human airway epithelia. Infect. Immun. 70, 4547-4555. doi: 10.1128/iai.70.8.4547-4555.2002

Scott, A. E., Laws, T. R., D’Elia, R. V., Stokes, M. G., Nandi, T., Williamson, E. D., et al. (2013). Protection against experimental melioidosis following immunization with live Burkholderia thailandensis expressing a manno-heptose capsule. Clin. Vaccine Immunol. 20, 1041-1047. doi: 10.1128/CVI.00113-13

Silva, E. B., and Dow, S. W. (2013). Development of Burkholderia mallei and pseudomallei vaccines. Front. Cell. Infect. Microbiol. 3:10. doi: $10.3389 /$ fcimb. 2013.00010

Sim, S. H., Liu, Y., Wang, D., Novem, V., Sivalingam, S. P., Thong, T. W., et al. (2009). Innate immune responses of pulmonary epithelial cells to Burkholderia pseudomallei infection. PLoS ONE 4:e7308. doi: 10.1371/journal.pone.0007308 Sitthidet, C., Korbsrisate, S., Layton, A. N., Field, T. R., Stevens, M. P., and Stevens, J. M. (2011). Identification of motifs of Burkholderia pseudomallei bima required for intracellular motility, actin binding, and actin polymerization. J. Bacteriol. 193, 1901-1910. doi: 10.1128/JB.01455-10

Speert, D. P., Henry, D., Vandamme, P., Corey, M., and Mahenthiralingam, E. (2002). Epidemiology of Burkholderia cepacia complex in patients with cystic fibrosis, canada. Emerging Infect. Dis. 8, 181-187. doi: 10.3201/eid0802.010163

Stevens, J. M., Galyov, E. E., and Stevens, M. P. (2006). Actin-dependent movement of bacterial pathogens. Nat. Rev. Microbiol. 4, 91-101. doi: $10.1038 /$ nrmicro 1320

Stevens, M. P., Friebel, A., Taylor, L. A., Wood, M. W., Brown, P. J., Hardt, W. D., et al. (2003). A Burkholderia pseudomallei type iii secreted protein, bope, facilitates bacterial invasion of epithelial cells and exhibits guanine nucleotide exchange factor activity. J. Bacteriol. 185, 4992-4996. doi: 10.1128/JB.185.16.4992-4996.2003

Stevens, M. P., and Galyov, E. E. (2004). Exploitation of host cells by Burkholderia pseudomallei. Int. J. Med. Microbiol. 293, 549-555. doi: 10.1078/1438-422100292

Stevens, M. P., Stevens, J. M., Jeng, R. L., Taylor, L. A., Wood, M. W., Hawes, P., et al. (2005). Identification of a bacterial factor required for actin-based motility of Burkholderia pseudomallei. Mol. Microbiol. 56, 40-53. doi: 10.1111/j.13652958.2004.04528.x

Stevens, M. P., Wood, M. W., Taylor, L. A., Monaghan, P., Hawes, P., Jones, P. W., et al. (2002). An inv/mxi-spa-like type iii protein secretion system in Burkholderia pseudomallei modulates intracellular behaviour of the pathogen. Mol. Microbiol. 46, 649-659. doi: 10.1046/j.1365-2958.2002.03190.x

Stoner, G. D., Kikkawa, Y., Kniazeff, A. J., Miyai, K., and Wagner, R. M. (1975). Clonal isolation of epithelial-cells from mouse lung adenoma. Cancer Res. 35, $2177-2185$ 
Tam, A., Wadsworth, S., Dorscheid, D., Man, S. F., and Sin, D. D. (2011). The airway epithelium: more than just a structural barrier. Ther. Adv. Respir. Dis. 5, 255-273. doi: 10.1177/1753465810396539

Taylor, J. B., Hogue, L. A., LiPuma, J. J., Walter, M. J., Brody, S. L., and Cannon, C. L. (2010). Entry of burkholderia organisms into respiratory epithelium: Cftr, microfilament and microtubule dependence. J. Cyst. Fibros. 9, 36-43. doi: 10.1016/j.jcf.2009.10.002

Techawiwattanaboon, T., Bartpho, T., Sermswan, R. W., and Chareonsudjai, S. (2015). Transcription level analysis of intracellular Burkholderia pseudomallei illustrates the role of bpsl1502 during bacterial interaction with human lung epithelial cells. J. Microbiol. 53, 134-140. doi: 10.1007/s12275-015-4522-9

Tipper, J. L., Ingham, E., Cove, J. H., Todd, N. J., and Kerr, K. G. (1998). Survival and multiplication of Burkholderia cepacia within respiratory epithelial cells. Clin. Microbiol. Infect. 4, 450-459. doi: 10.1111/j.1469-0691.1998.tb00394.x

Tomich, M., Herfst, C. A., Golden, J. W., and Mohr, C. D. (2002). Role of flagella in host cell invasion by Burkholderia cepacia. Infect. Immun. 70, 1799-1806. doi: 10.1128/IAI.70.4.1799-1806.2002

Ulett, G. C., Labrooy, J. T., Currie, B. J., Barnes, J. L., and Ketheesan, N. (2005). A model of immunity to Burkholderia pseudomallei: unique responses following immunization and acute lethal infection. Microb. Infect. 7, 1263-1275. doi: 10.1016/j.micinf.2005.04.013

Ulrich, R. L., and DeShazer, D. (2004). Type iii secretion: a virulence factor delivery system essential for the pathogenicity of Burkholderia mallei. Infect. Immun. 72, 1150-1154. doi: 10.1128/iai.72.2.1150-1154.2004

Urban, T. A., Goldberg, J. B., Forstner, J. F., and Sajjan, U. S. (2005). Cable pili and the 22-kilodalton adhesin are required for Burkholderia cenocepacia binding to and transmigration across the squamous epithelium. Infect. Immun. 73, 5426-5437. doi: 10.1128/IAI.73.9.5426-5437.2005

Utaisincharoen, P., Arjcharoen, S., Lengwehasatit, I., Limposuwan, K., and Sirisinha, S. (2005). Burkholderia pseudomallei invasion and activation of epithelial cells requires activation of p38 mitogen-activated protein kinase. Microb. Pathog. 38, 107-112. doi: 10.1016/j.micpath.2004.12.006

Van Zandt, K. E., Greer, M. T., and Gelhaus, H. C. (2013). Glanders: an overview of infection in humans. Orphanet J. Rare Dis. 8:131. doi: 10.1186/1750-1172-8-131

Vareille, M., Kieninger, E., Edwards, M. R., and Regamey, N. (2011). The airway epithelium: soldier in the fight against respiratory viruses. Clin. Microbiol. Rev. 24, 210-229. doi: 10.1128/CMR.00012-11

Wang, K., Lu, C., and Fan, W. (2011). Bacterial capsular polysaccharide-a review. Acta Microbiol. Sin. 51, 1578-1584.

West, T. E., Chantratita, N., Chierakul, W., Limmathurotsakul, D., Wuthiekanun, V., Myers, N. D., et al. (2013). Impaired tlr5 functionality is associated with survival in melioidosis. J. Immunol. 190, 3373-3379. doi: 10.4049/jimmunol.1202974

West, T. E., Ernst, R. K., Jansson-Hutson, M. J., and Skerrett, S. J. (2008). Activation of toll-like receptors by Burkholderia pseudomallei. BMC Immunol. 9:46. doi: 10.1186/1471-2172-9-46

West, T. E., Hawn, T. R., and Skerrett, S. J. (2009). Toll-like receptor signaling in airborne Burkholderia thailandensis infection. Infect. Immun. 77, 5612-5622. doi: 10.1128/IAI.00618-09

West, T. E., Myers, N. D., Liggitt, H. D., and Skerrett, S. J. (2012). Murine pulmonary infection and inflammation induced by inhalation of
Burkholderia pseudomallei. Int. J. Exp. Pathol. 93, 421-428. doi: 10.1111/j.13652613.2012.00842.x

Whitlock, G. C., Valbuena, G. A., Popov, V. L., Judy, B. M., Estes, D. M., and Torres, A. G. (2009). Burkholderia mallei cellular interactions in a respiratory cell model. J. Med. Microbiol. 58, 554-562. doi: 10.1099/jmm.0.007724-0

Wiersinga, W. J., and van der Poll, T. (2009). Immunity to Burkholderia pseudomallei. Curr. Opin. Infect. Dis. 22, 102-108. doi: 10.1097/QCO.0b013e328322e727

Wiersinga, W. J., Wieland, C. W., Dessing, M. C., Chantratita, N., Cheng, A. C., Limmathurotsakul, D., et al. (2007). Toll-like receptor 2 impairs host defense in gram-negative sepsis caused by Burkholderia pseudomallei (melioidosis). PLoS Med. 4:e248. doi: 10.1371/journal.pmed.0040248

Wongprompitak, P., Sirisinha, S., and Chaiyaroj, S. C. (2009). Differential gene expression profiles of lung epithelial cells exposed to Burkholderia pseudomallei and Burkholderia thailandensis during the initial phase of infection. Asian Pac. J. Allergy Immunol. 27, 59-70.

Wright, C., Pilkington, R., Callaghan, M., and McClean, S. (2011). Activation of mmp-9 by human lung epithelial cells in response to the cystic fibrosis-associated pathogen Burkholderia cenocepacia reduced wound healing in vitro. Am. J. Physiol. Lung Cell. Mol. Physiol. 301, L575-L586. doi: 10.1152/ajplung.00226.2010

Wu, Q., Jiang, D., Minor, M. N., Martin, R. J., and Chu, H. W. (2011). In vivo function of airway epithelial tlr2 in host defense against bacterial infection. Am. J. Physiol. Lung Cell. Mol. Physiol. 300, L579-L586. doi: 10.1152/ajplung.00336.2010

Wuthiekanun, V., Amornchai, P., Saiprom, N., Chantratita, N., Chierakul, W., Koh, G. C., et al. (2011). Survey of antimicrobial resistance in clinical Burkholderia pseudomallei isolates over two decades in northeast thailand. Antimicrob. Agents Chemother. 55, 5388-5391. doi: 10.1128/AAC.05517-11

Zeitlin, P. L., Lu, L., Rhim, J., Cutting, G., Stetten, G., Kieffer, K. A., et al. (1991). A cystic-fibrosis bronchial epithelial-cell line - immortalization by adeno-12-sv40 infection. Am. J. Respir. Cell Mol. Biol. 4, 313-319. doi: 10.1165/ajrcmb/4.4.313

Zhang, Z., Louboutin, J. P., Weiner, D. J., Goldberg, J. B., and Wilson, J. M. (2005). Human airway epithelial cells sense Pseudomonas aeruginosa infection via recognition of flagellin by toll-like receptor 5. Infect. Immun. 73, 7151-7160. doi: 10.1128/IAI.73.11.7151-7160.2005

Zong, Z., Wang, X., Deng, Y., and Zhou, T. (2012). Misidentification of Burkholderia pseudomallei as Burkholderia cepacia by the vitek 2 system. J. Med. Microbiol. 61, 1483-1484. doi: 10.1099/jmm.0.041525-0

Conflict of Interest Statement: The authors declare that the research was conducted in the absence of any commercial or financial relationships that could be construed as a potential conflict of interest.

Copyright (c) 2015 HM Government (United Kingdom). Authors: David, Bell and Clark. This is an open-access article distributed under the terms of the Creative Commons Attribution License (CC BY). The use, distribution or reproduction in other forums is permitted, provided the original author(s) or licensor are credited and that the original publication in this journal is cited, in accordance with accepted academic practice. No use, distribution or reproduction is permitted which does not comply with these terms. 